\title{
Paleoecology as a guide to landscape conservation and restoration in the neotropical Gran Sabana
}

\author{
Valentí Rull1', T. Vegas-Vilarrúbia² and E. Montoya ${ }^{1}$
}

\begin{abstract}
Late Pleistocene and Holocene paleoecological reconstructions from the neotropical Gran Sabana provide objective criteria to assess realistic and feasible restoration targets, and to appraise the potential effects of global warming on the landscapes and ecosystems.
\end{abstract}

A significant contribution of paleoecology to conservation and restoration practices is its ability to provide evidence of past ecological conditions, thereby permitting the identification of baselines, to which it would be desirable to return. Choosing the most desirable target is the first step in restoration planning, and $a$ frequent option is to choose to restore the ecological conditions that existed prior to human disturbance (Willis et al. 2010). Another relevant conservation output that may be derived from paleoecological records is the response of ecological communities to past climate change as a model for anticipating potential ecological responses to future climate change (Vegas-Vilarrúbia et al. 2011). Here, we use these approaches to analyze the case of the Gran Sabana region, located in northern South America.

The Gran Sabana is part of a huge savanna island within the Amazon-Orinoco rainforests (Fig. 1). Most of the Gran Sabana is covered by treeless savannas, with forestsavanna mosaics at the edges and gallery forests along rivers. A special type of gallery forest is the emblematic palm swamp of Mauritia flexuosa, locally known as "morichal" (Rull and Montoya 2014). The Gran Sabana is part of the Canaima National Park, in the headwaters of the Caroní River, a tributary of the Orinoco that is exploited for hydroelectric power. The savannas are nowadays in expansion to the detriment of forests, mainly due to burning by indigenous people, sparking a debate between defenders and detractors of these practices. Defenders argue that fire management is a fundamental part of indigenous traditions and should be preserved, while critics believe that fires have been responsible for the disappearance of the hypothetical ancient forests that covered the Gran Sabana before the onset of fire practices. This debate is relevant for conservation, as the detractors of indigenous practices argue that forest clearance should cease, whereas the indigenous defenders believe that fires are useful for land management and should be included in conservation planning (Sletto and Rodríguez 2013).

\section{Paleoecology and restoration targets}

The Gran Sabana paleoecological records extend back to the Younger Dryas, when it was covered by a mosaic of forests, shrublands and savanna patches. The vegetation cover was mostly ligneous but a continuous
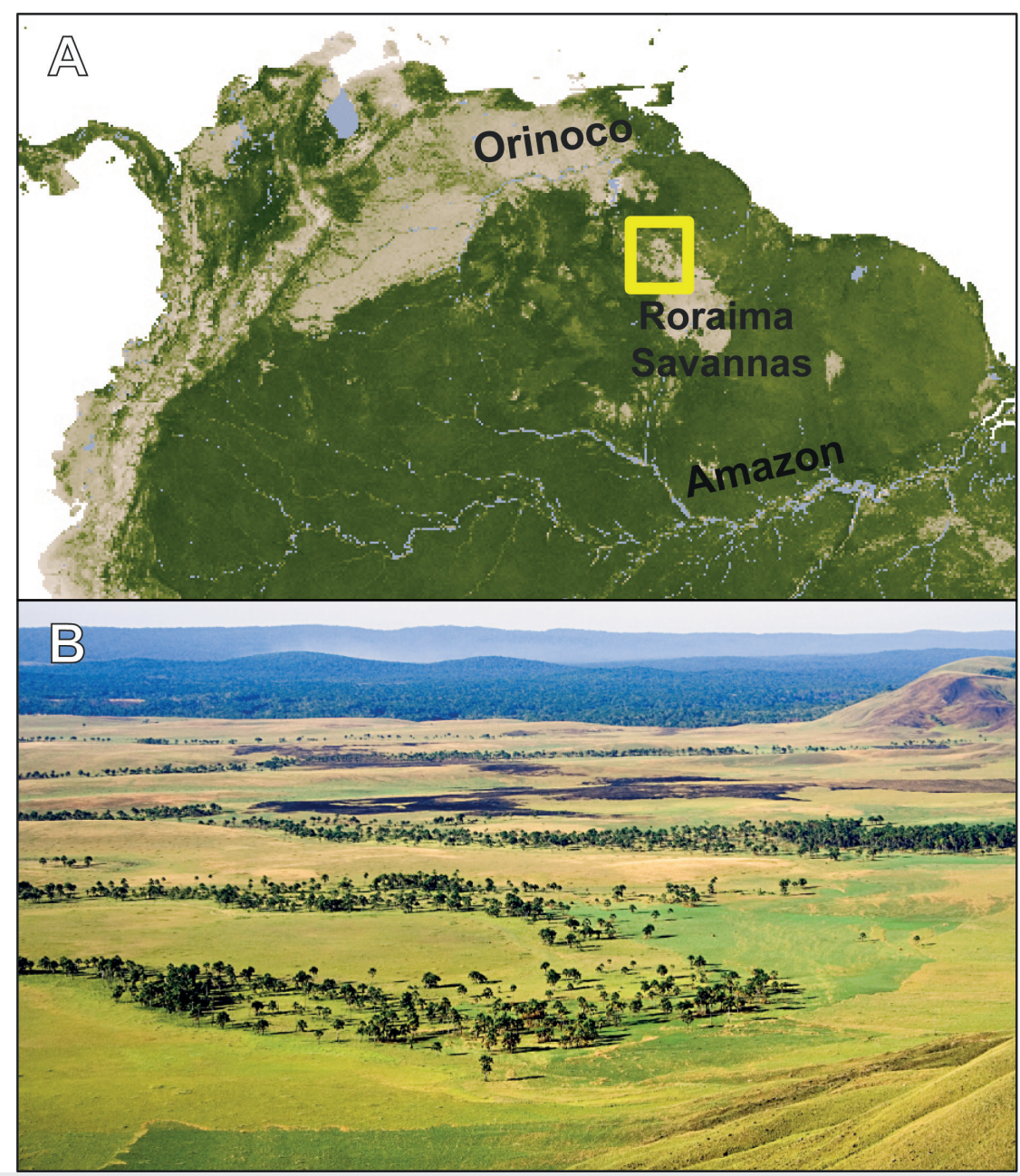

Figure 1: The Gran Sabana. (A) Map of northern South America showing the Roraima Savannas and the Gran Sabana (yellow box), between the Orinoco and Amazon basins. (B) Typical landscape of the Gran Sabana savannas and Mauritia palm swamps with dark patches corresponding to recent fires. The Orinoco-Amazon rainforests are in the background. Photo: V. Rull.

forest cover was not observed (Montoya et al. 2011a; Rull et al. 2013). The extensive savannization process started in the Younger Dryas-Holocene transition and culminated by ca. 10 cal ka BP (Fig. 2). Fires, possibly of anthropogenic origin, and the Early Holocene Warming seem to have been involved in this savannization trend, which was relatively rapid and hitherto irreversible (Rull et al. 2015a). During most of the Holocene, fires remained at low rates and the Gran Sabana was dominated by treeless savanna with gallery forests and without Mauritia palm swamps. Gallery forests experienced a significant increase during the middle
Holocene (ca. 7 to 5 cal ka BP), likely due to a general increase in the available moisture (Montoya et al. 2011b; Rull et al. 2016). Mauritia flexuosa arrived to the Gran Sabana by 2 cal ka BP, coinciding with a significant exacerbation of fire, considered to be the onset of the present-like indigenous fire management practices, and the establishment of modern Gran Sabana landscapes (Montoya and Rull 2011; Montoya et al. 2011c; Fig. 2). During the last 2000 years, Mauritia swamps have experienced a remarkable expansion because they are not burnt by indigenous people, who use this palm for multiple purposes (Rull and Montoya 2014). 
In summary, we have identified three general ecological states since the Late Glacial: (i) a forest-shrubland-savanna mosaic dominated by ligneous communities during the Younger Dryas, (ii) extended treeless savannas with gallery forests during most of the Holocene, and (iii) treeless savannas with gallery forests and Mauritia palm swamps during the last 2000 years. It is possible that the number of ecological states will increase as further studies on glacial and former times are conducted. Two other potential states not observed in the available past ecological records are: (iv) treeless savannas totally devoid of forests and (v) continuous forest cover without savannas. On the basis of paleoecological studies, both of these scenarios would be unrealistic as a conservation target.

\section{Restoration proposals}

Using the criterion of pre-human conditions (target i) would be problematic, because Younger Dryas climatic conditions differed from those of today, and because this would be in conflict with present-day indigenous practices. Restoring the prevalent Holocene conditions (target ii) would necessitate the removal of the emblematic Mauritia palm swamps, which would be a very unpopular proposal, involving the destruction of the present-day Gran Sabana landscape that is generally regarded as "natural". Moreover, it would be difficult to develop such actions in a national park created on the basis of current landscape features. In addition, Mauritia flexuosa is a key resource for indigenous people over the entire Neotropics (Rull and Montoya 2014), and its removal would be viewed as cultural aggression. The third option (target iii) - maintaining the Gran Sabana as it is at present - implicitly accepts the continued use of fire by the indigenous people, a condition that would not be acceptable to the defenders of the assumed continuity of former hypothetical rainforests. Because it does not require any special action, this option would be the least expensive in terms of budget and effort; however, its likely consequence will be the continued expansion of savannas to the detriment of rainforests. An alternative solution, at least in theory, would be the joint recreation of present and former ecological states (i, ii and iii) in different parts of the Gran Sabana. This option has been called conservation quasi in situ or inter situ (Burney and Burney 2007; Volis and Blecher 2010); its main drawbacks are that large investments are required to create and maintain such structures and that it would imply intervention into indigenous land-use practices, which is very problematic under the current socio-political circumstances (Rull et al. 2016).

\section{Responses to global warming}

The Younger Dryas-Early Holocene warming has been proposed as a past analogue of future global warming in the Neotropics (Rull et al. 2015b). According to the latest IPCC report, by 2100 the Gran Sabana region will experience an average temperature increase of $2-3^{\circ} \mathrm{C}$, whereas precipitation will remain at similar-to-present values, with a range of variation of $20 \%$ (IPCC 2013). This scenario is

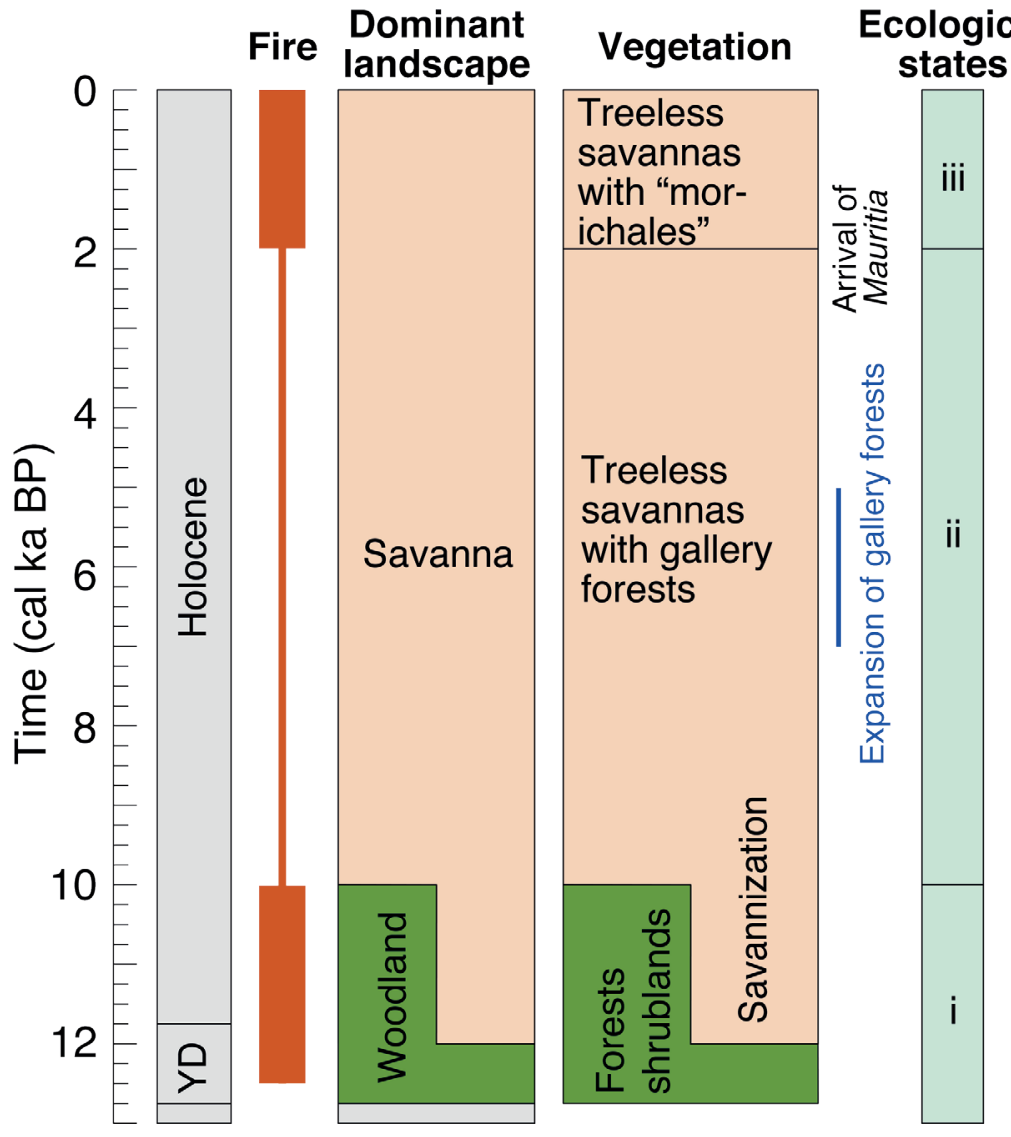

Figure 2: Synthesis of the main paleoecological trends during the last 13,000 years. The ecological states i, ii and iii are described in the text. Modified from Rull et al. (2016).

similar to the Younger Dryas-Early Holocene warming transition, when treeless savannas already dominated the Gran Sabana landscape and the incoming of wetter climates was not sufficient for forest recovery, likely due to fire continuity. As stated earlier this savannization process was irreversible until today. Using this model, it can be predicted that continuation of present-day fire practices will likely result in the irreversible expansion of savannas and a concomitant reduction of forests, similar to that observed historically. Therefore, fire control measures should be agreed upon with indigenous people if the remaining Gran Sabana forests are to be preserved in their present state (target iii). If a landscape of treeless savanna devoid of forests and spiked with morichales is the desired conservation target (scenario iv), then no action is required. Again, the recovery of the pre-human Younger Dryas landscape (target i) seems unattainable under the IPCC predictions, using the past analogue scenario depicted here. For similar reasons, total reforestation of the Gran Sabana (scenario v) would be unworkable.

\section{Conservation policy}

All these considerations and others that have emerged from paleoecological studies should be evaluated by the stakeholders and policy-makers as a basis for developing the best conservation strategy. The role of paleoecologists is to provide the necessary information on aspects of temporal ecological dynamics that may be pertinent to conservation and possible restoration targets. Paleoecological information should be part of these deliberations; otherwise, conservation targets will be unrealistic and landscape development under the action of environmental drivers will be unpredictable.

\section{AFFILIATIONS}

'Laboratory of Paleoecology, Institute of Earth Sciences Jaume Almera (ICTJA-CSIC), Barcelona, Spain

2Department of Evolutionary Biology, Ecology and Environmental Sciences, University of Barcelona, Spain

\section{CONTACT}

Valentí Rull:vrull@ictja.csic.es

\section{REFERENCES}

Burney DA, Burney LP (2007) Front Ecol Environ 5: 483-490

IPCC (2013) Climate Change 2013. The Physical Science Basis, Cambridge University Press

Montoya E, Rull V (2011) Quat Sci Rev 30: 3430-3444 Montoya E et al. (2011a) J Quat Sci 26: 207-218 Montoya et al. (2011b) Palaeogeogr Palaeoclimatol Palaeoecol 310: 413-426

Montoya et al. (2011c) Quat Res 76: 335-344 Rull V, Montoya E (2014) Quat Sci Rev 99: 17-33 Rull V et al. (2013) Persp Plant Ecol Evol Syst 15: 338-359 Rull V et al. (2015a) Quat Sci Rev 122: 158-165 Rull V et al. (2015b) Quat Sci Rev 115: 28-38 Rull V et al. (2016) Holocene 26: 1162-1167 Sletto B, Rodríguez I (2013) J Environ Manag 115: 155-166 Vegas-Vilarrúbia T et al. (2011) Quat Sci Rev 30: 2361-2388 Volis S, Blecher M (2010) Biodiv Conserv 19: 2441-2454 Willis KJ et al. (2010) Trends Ecol Evol 25: 583-591 